\title{
CASTILLO DE TEAYO
}

\section{P O R}

\section{R A U L F L O RES G U E R E R O}

$7_{\mathrm{N}}^{\mathrm{N}}$ el mes de diciembre de 1902 Eduardo Seler --ese extraordinario precursor de la antropología moderna en México cuya obra, inexplicablemente, permanece aún inédita en español - realizó un recorrido de investigación por la región veracruzana cercana a Tuxpan tomando como centro de sus actividades un poblado apenas conocido: Castillo de Teayo. Allí pasó una semana acompañado de su esposa, fotografiando, midiendo y dibujando sus hallazgos, escribiendo sus notas, con una actividad admirable en medio de una insistente lluvia que nunca amenguaba.

El resultado de esa semana de trabajo fue un estudio extenso y cuidadoso, como todos los suyos, que dio a conocer año y medio más tarde en una conferencia sustentada en el $X I V$ Congreso Internacional de Americanistas celebrado en Stuttgart: Die Alterthïmer von Castillo de Teayo; estudio tan completo e importante que, hasta la fecha, continúa siendo una referencia inevitable para cualquier ensayo que se intente sobre ese sitio arqueológico.

El presente escrito pretende ser una visión actual de Castillo de Teayo. En ella se considerarán los monumentos prehispánicos más importantes desde un punto de vista no tanto arqueológico sino artístico. Además, como lógica consecuencia, tiende a establecer la importancia que este pueblo tuvo, en la antigüedad, como centro de concurrencia de diversas influencias culturales. 
A juzgar por el "estilo" de los diferentes monumentos arqueológi$\cos$ Teayo - que en lengua mexicana quiere decir "lugar acuático y pedregoso"- fue en la época precolombina un centro indígena huasteco influenciado primero por la cultura tolteca $y$, en fechas cercanas a la conquista española, por la cultura azteca. De acuerdo con esto su florecimiento puede situarse entre el siglo $x \mathrm{u}$ xI $\mathrm{d}$. C., $\mathrm{y}$ las primeras décadas del siglo xvi aproximadamente. Seler asegura que "en la época de la Conquista fue abandonado el pueblo fundado por los mexicanos..." $\mathrm{Y}$ añade: "hace como treinta y dos o treinta y tres años (es decir, alrededor de 1870) que la gente de Tihuatlán emprendió la tarea de destruir el bosque a fin de destinar el fértil suelo a potreros y milpas... Una vez que hubo coronado esta obra, quemando la selva, edificó un nuevo pueblo... en un lugar aireado y libre... precisamente en torno de la antigua pirámide dejando a ésta en el centro de la plaza. Y Castillo (esto es, pirámide) de Teayo se llama hoy el villorrio para distinguirlo de la antigua Hacienda de Teayo." 1

\section{La pirámide}

Cincuenta y seis años después de la visita de Seler y como en la época prehispánica la pirámide continúa siendo el corazón del poblado. A su alrededor se encuentra el jardín público, con sus árboles, sus prados descuidados $\mathrm{y}$ sus bancas, entre las que se levantan ordenadamente las esculturas monoliticas que han sido halladas a través de los años en los alrededores. El templo - uno de los pocos que conservan en el área nahua su estructura original- situado en la cúspide de la pirámide, ha sido cubierto a íltimas fechas por un techo de palma a dos aguas, acorde en sus líneas con el conjunto. En su interior cuelgan de un grueso madero, patinado por los años, las campanas que sirven a la comunidad como anuncio de reuniones civiles e incluso religiosas.

Los tres cuerpos en talud del basamento piramidal están construídos sobre un núcleo de piedras y barro y recubiertos con lajas de cantera ordenadas en hiladas horizontales. De trecho en trecho sobresalen del paño general de los taludes las piedras que servían para afirmar el aplanado de estuco coloreado que originalmente decoraba el monumento.

1 Seler, Eduard. Die Alterthïmer von Castillo de Teayo. Gesammelte Abhandlungen aur Amerikanishen Sprach und Alterthumskunde. Berlín, 1904, vol. 3, pp. 410 a 449. (Traducción en español inédita en la Biblioteca del Museo Nacional.) 
Los perfiles de los tres taludes escalonados de la pirámide son de una acentuada verticalidad y tienden a producir un sentimiento de ascención con su imperioso impulso hacia arriba que se enfatiza por la escalinata peraltada a lo máximo. A los lados de esta última dos macizos contrafuertes, escalonados como los cuerpos del monumento, imprimen mayor monumentalidad al edificio proyectando su volumen hacia adelante con una ambición espacial excepcional en la arquitectura prehispánica.

Tanto los contrafuertes como las alfardas de la escalinata rompen su declive en la parte más alta para terminar verticalmente, estableciendo así una relación arquitectónica indiscutible con los edificios aztecas de este tipo. El aztequismo del monumento se confirma con la existencia de dos pequeñas esculturas sedentes, semejantes a las que servían de portaestandartes en los descansos de los cuerpos de la pirámide mayor de Tenochtitlán, las cuales indudablemente tuvieron la misma función en la de Teayo. Es en virtud de esto que se hace incomprensible que los arqueólogos José García Payón ${ }^{2}$ y Rafael Orellana ${ }^{3}$ nieguen el carácter azteca del monumento; más aún cuando Seler explica tan convincentemente la colonización de la región por los mexicanos con argumentos históricos que tienen su confirmación arqueológica en cada una de las esculturas aztecas que hoy pueden admirarse al pie de la pirámide. Es cierto que García Payón asienta que, en Teayo, "se trasplantó en una época tardía, todavía no determinada, una importante rama de la cuitura tolteca de Tula", lo que en gran parte es cierto como lo demuestran algunas otras esculturas, pero la pirámide en sí no puede ser más azteca en sus lineamientos arquitectónicos. Si acaso existió una subestructura tolteca las escasas exploraciones llevadas a cabo no han podido aún demostrarlo.

\section{El templo}

El templo, actual reducto de las campanas del pueblo, conserva todavía restos de su piso original, estucado al igual que los muros. Estos últimos se levantan sobre un pequeño talud que les sirve de base engro-

2 García Payón, José. Impresiones de mi primera visita a Castillo de Teaya en 1944. Original inédito en la Biblioteca del Instituto Nacional de Antropología e Historia. También en Sinopsis sobre algunos problemas arqueológicos del Tolonacapan. En “El México Antiguo”, vol. vi, 1947.

3 Orellana T., Rafael. Informe de los trabajos de reconstrucción y consolidación de Castillo de Teayo, Veracriz, durante la primera temporada de 1948. (Inédito en la Biblioteca del Instituto Nacional de Antropología e Historia.) 
sándose en el interior a medida que se acercan a la parte más alta en donde Seler, cuando estuvo alli, encontró vestigios de vigas to cual to indujo a pensar en que posiblemente existió "un departamento superior especial". Esta suposición, por más que parezca descabellada, no está lejos de ser posible puesto que en Cuauhtochco (Veracruz) se ha descubierto un templo que originalmente tuvo hasta tres pisos; ${ }^{4} \sin \mathrm{em}$ bargo, a la fecha, esos vestigios han desaparecido por completo.

\section{Las esculturas}

En el pequeño jardín que rodea a la pirámide se levantan numerosas esculturas monolíticas que los pobladores de Teayo han reunido alli a través de los años. Esculturas de diversos tamaños y de diferentes estilos halladas junto a la pirámide o en la cercanías del pueblo y que, más o menos ordenadas entre los escasos arbustos, constituyen un curioso $y$ extraño museo popular al aire libre.

La variación estilística en el tratamiento escultórico de estas piezas se explica en virtud de la influencia más o menos notable, según la época en que fueron hechas, de la cultura tolteca primero y después de la azteca sobre una población huasteca autóctona. Es así que se encuentran esculturas de un "huastequismo" casi intacto junto a otras en que el concepto de forma de la cultura local está de tal manera identificado con el de los toltecas que el resultado artístico es de tan peculiar diferenciación y regionalismo que las obras llegan a tener un "estilo" propio e inconfundible. Sólo en el caso de las esculturas aztecas el sello del arte mexicano es tan definitivo, tan poderoso, que de haberse descubierto en las ruinas de la antigua Tenochtitlán no hubieran causado ninguna sorpresa. Es natural que pasado el momento de nahuatlización de los primitivos habitantes huastecos de Castillo de Teayo, gracias al influjo tolteca, el arte azteca, aplastante por su profundo y dramático sentido de la escultura, se haya impuesto en forma radical.

Numerosas son las esculturas que aparecen en el jardín de Teayo. De ellas sólo haré referencia aquí a las que tienen un interés estético que son, por otra parte, las que más luces arrojan sobre la historia cultural del antiguo pueblo indigena.

4. Medellin Zenil, Alfonso. Exploraciones en Cuauhtochco. Gobierno del Estado de Veracruz. Departamento de Antropología, Jalapa, 1952. 


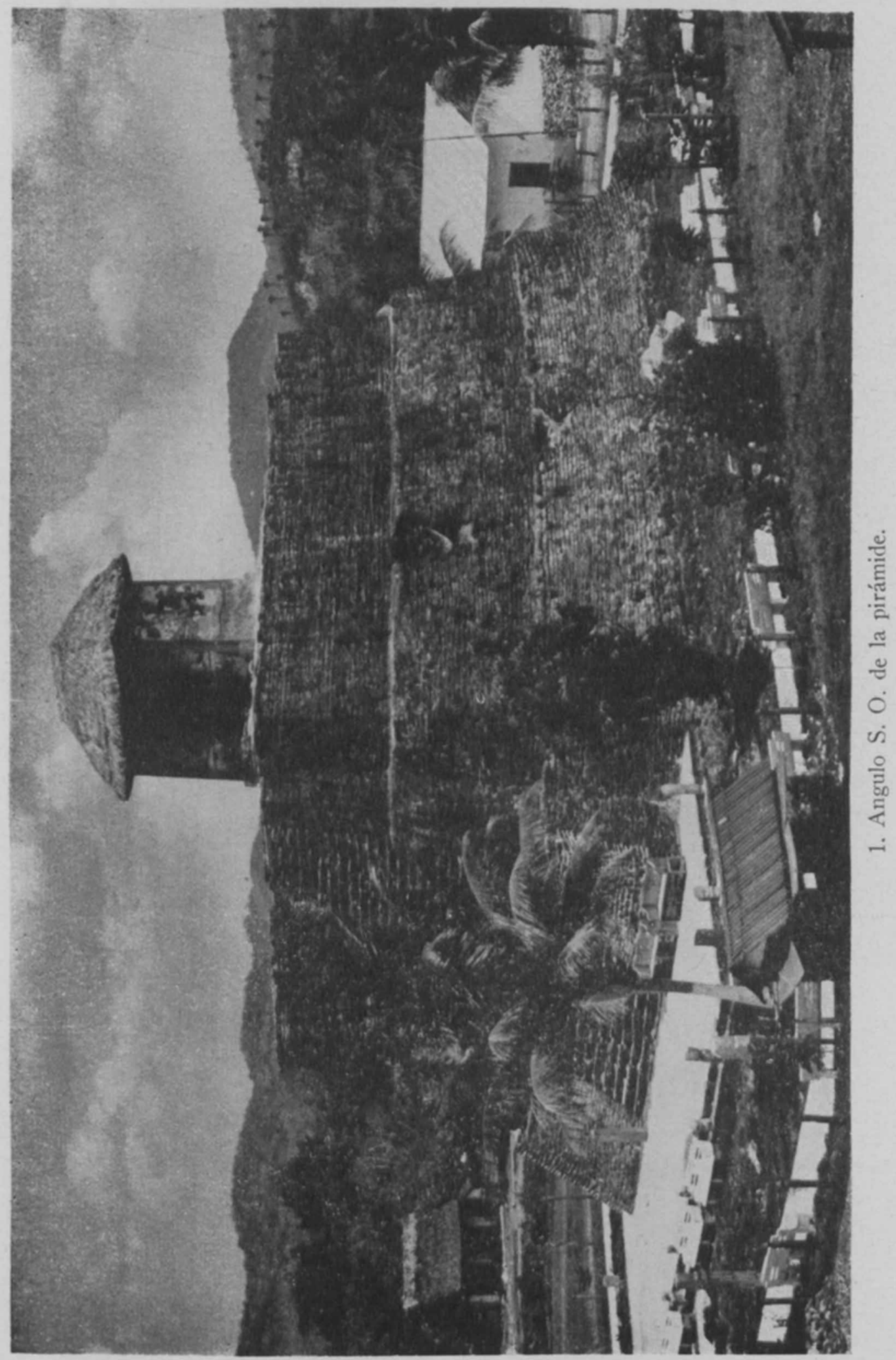


DOI: http://dx.doi.org/10.22201/iie.18703062e.1958.27.647

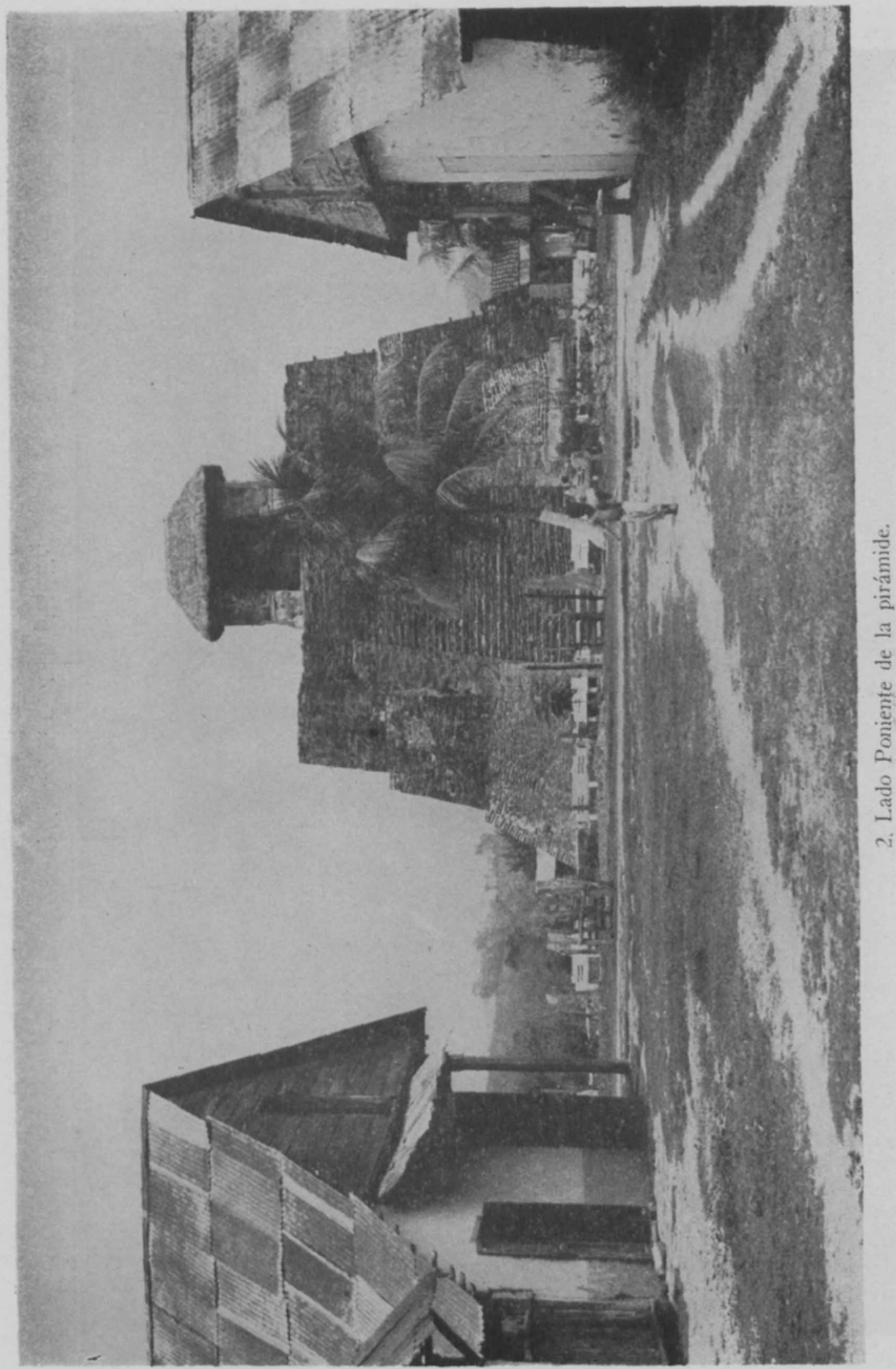


DOI: http://dx.doi.org/10.22201/iie.18703062e.1958.27.647

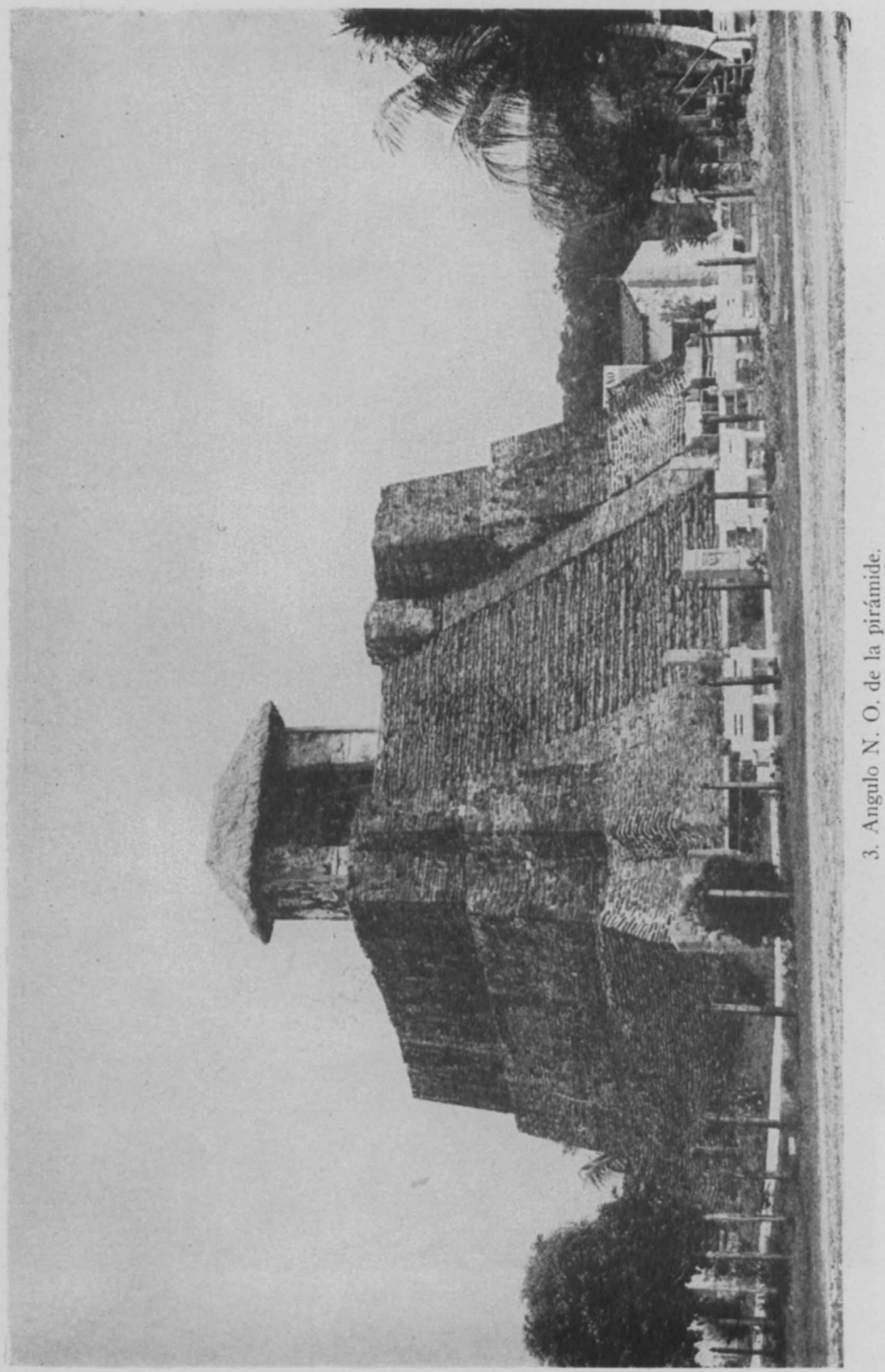


DOI: http://dx.doi.org/10.22201/iie.18703062e.1958.27.647

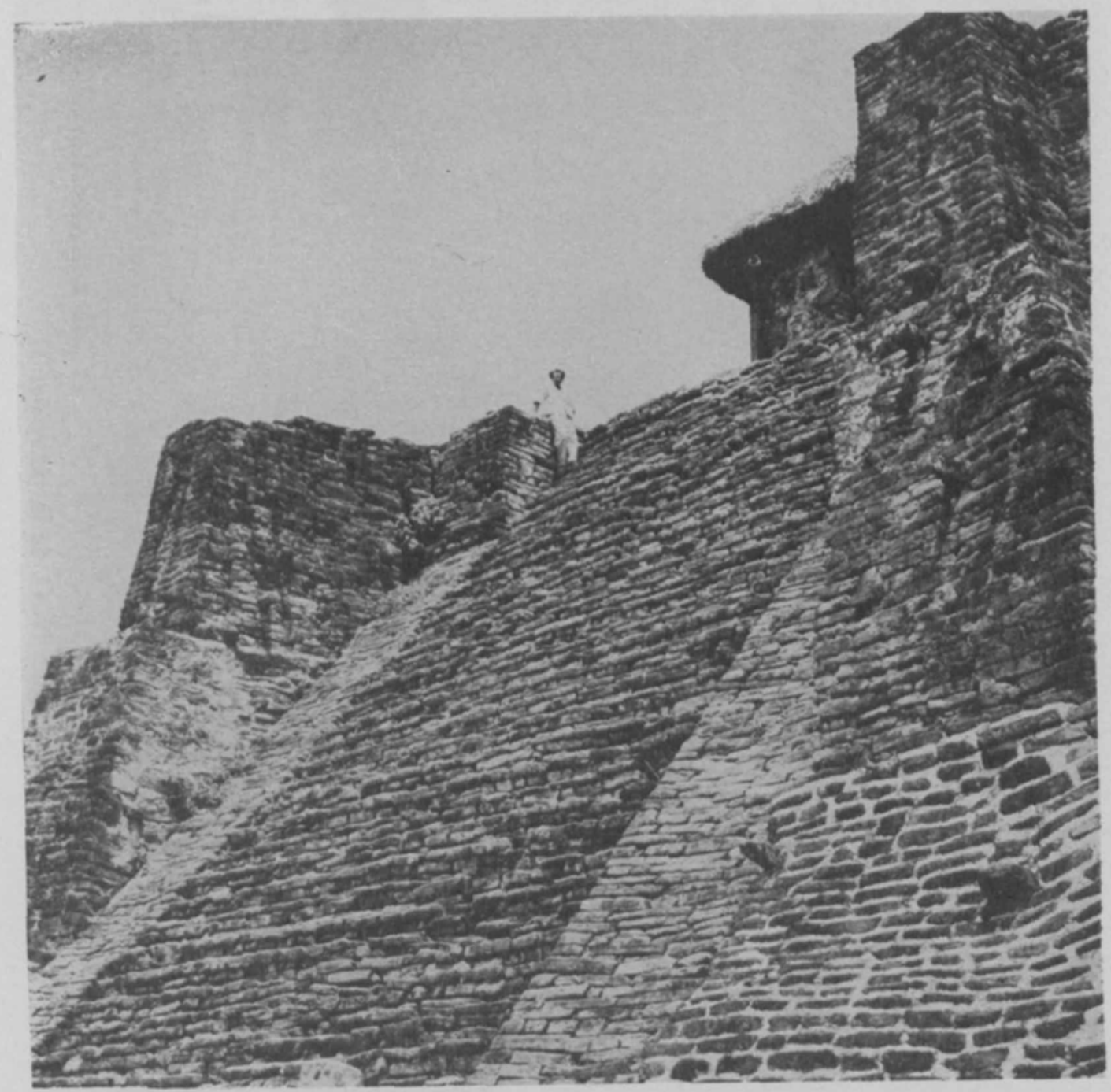

4. Escalinata de la pirámide. 
DOI: http://dx.doi.org/10.22201/iie.18703062e.1958.27.647

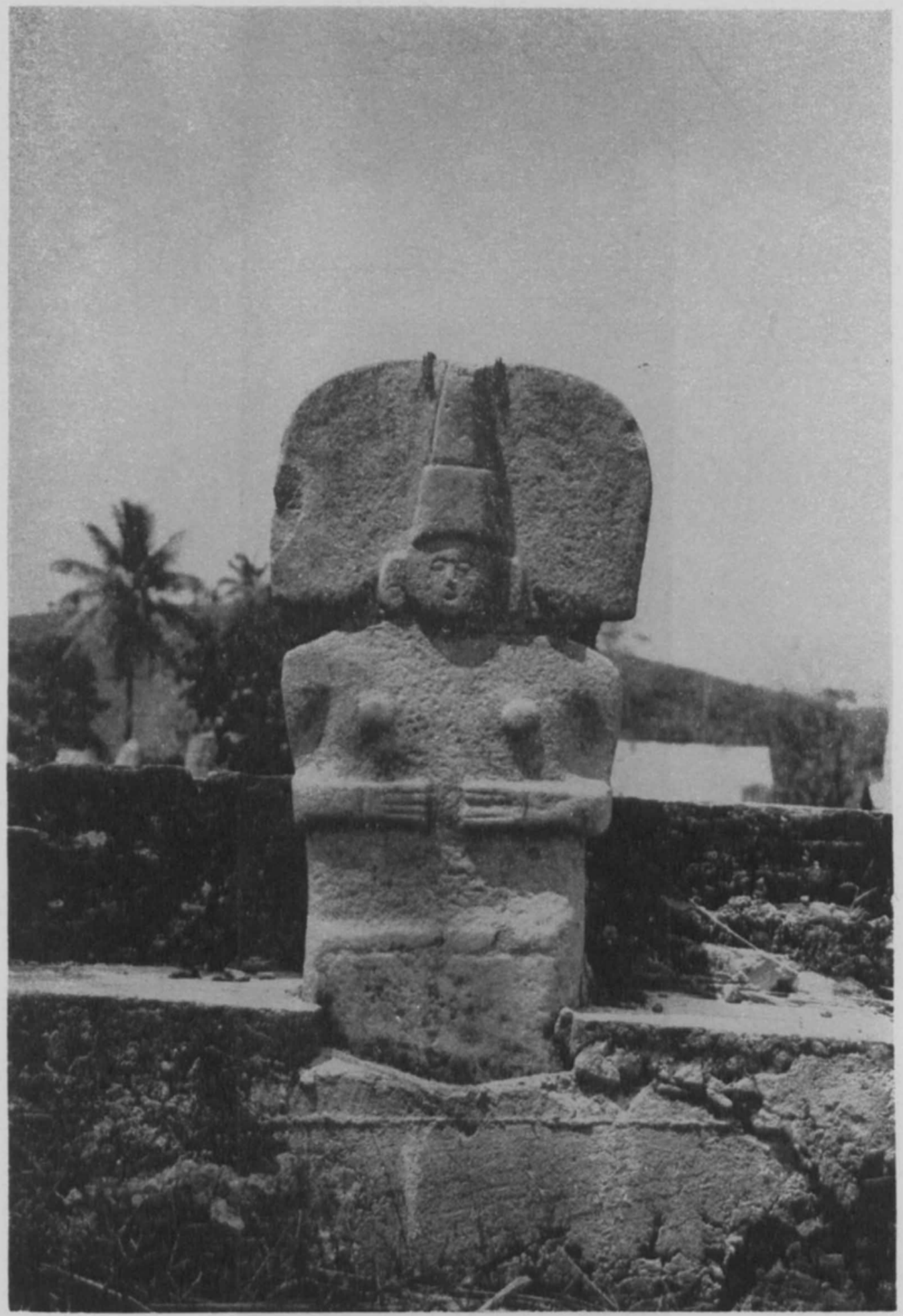

5. Ixcuiname. Escultura huaxteca. 


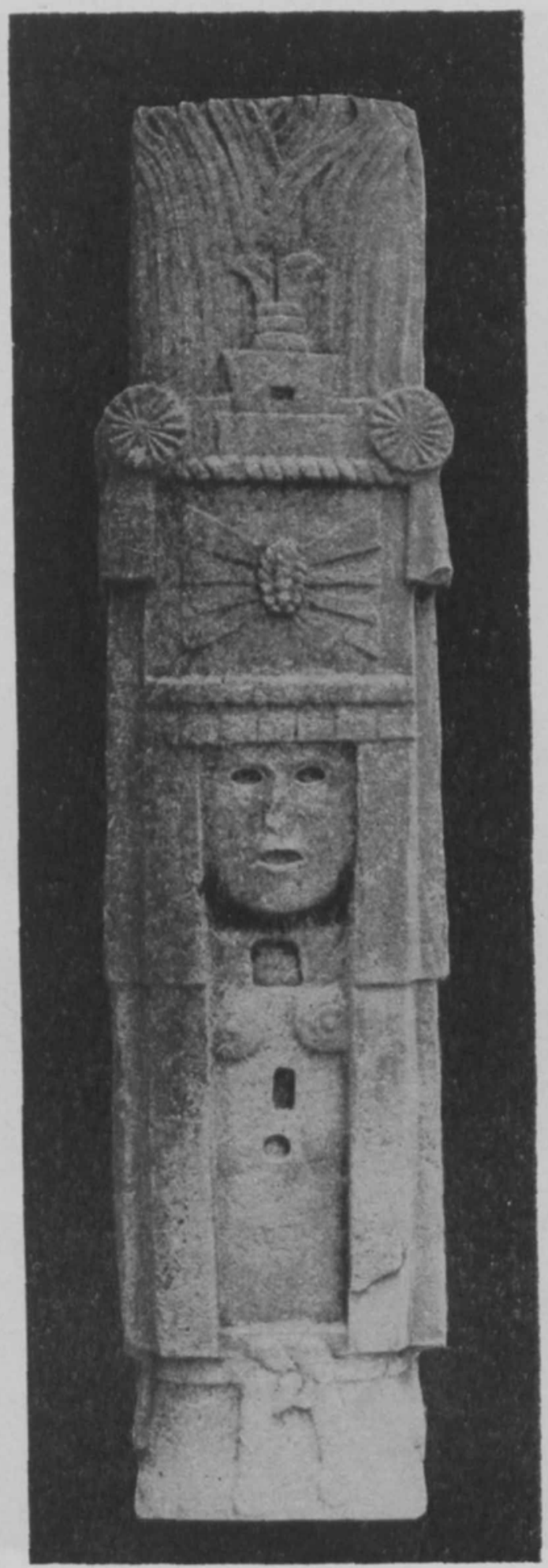

6. Chicomecoatl. Diosa de los mantenimientos. 
DOI: http://dx.doi.org/10.22201/iie.18703062e.1958.27.647

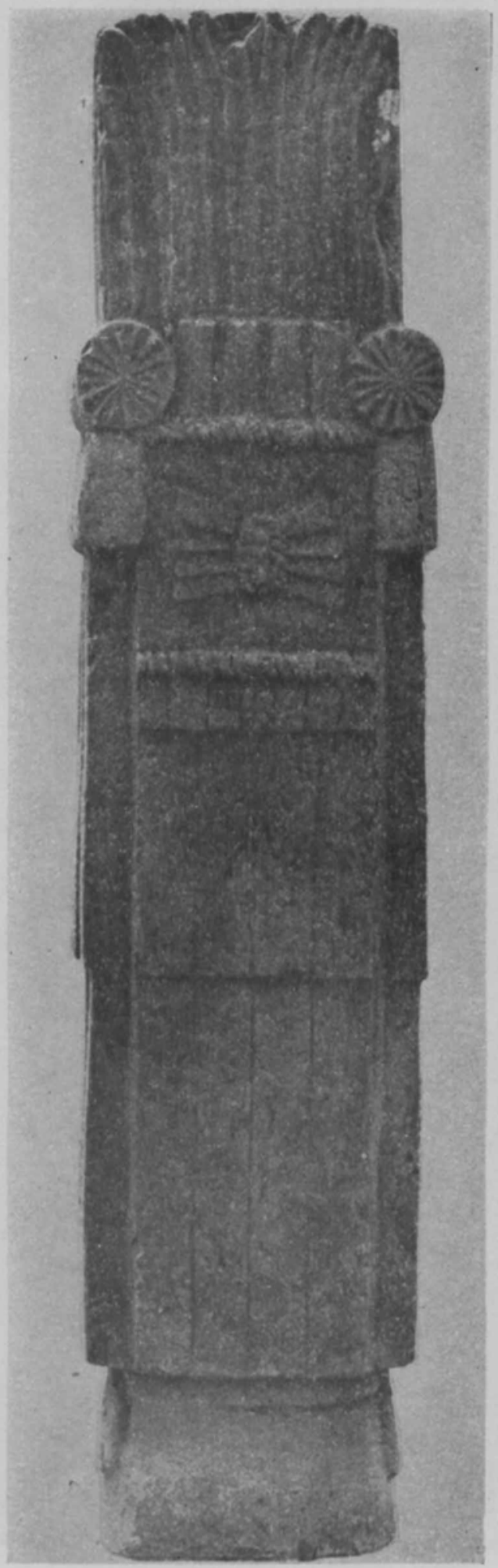

7. Chicomecoatl. Diosa de los mantenimientos (lado posterior). 


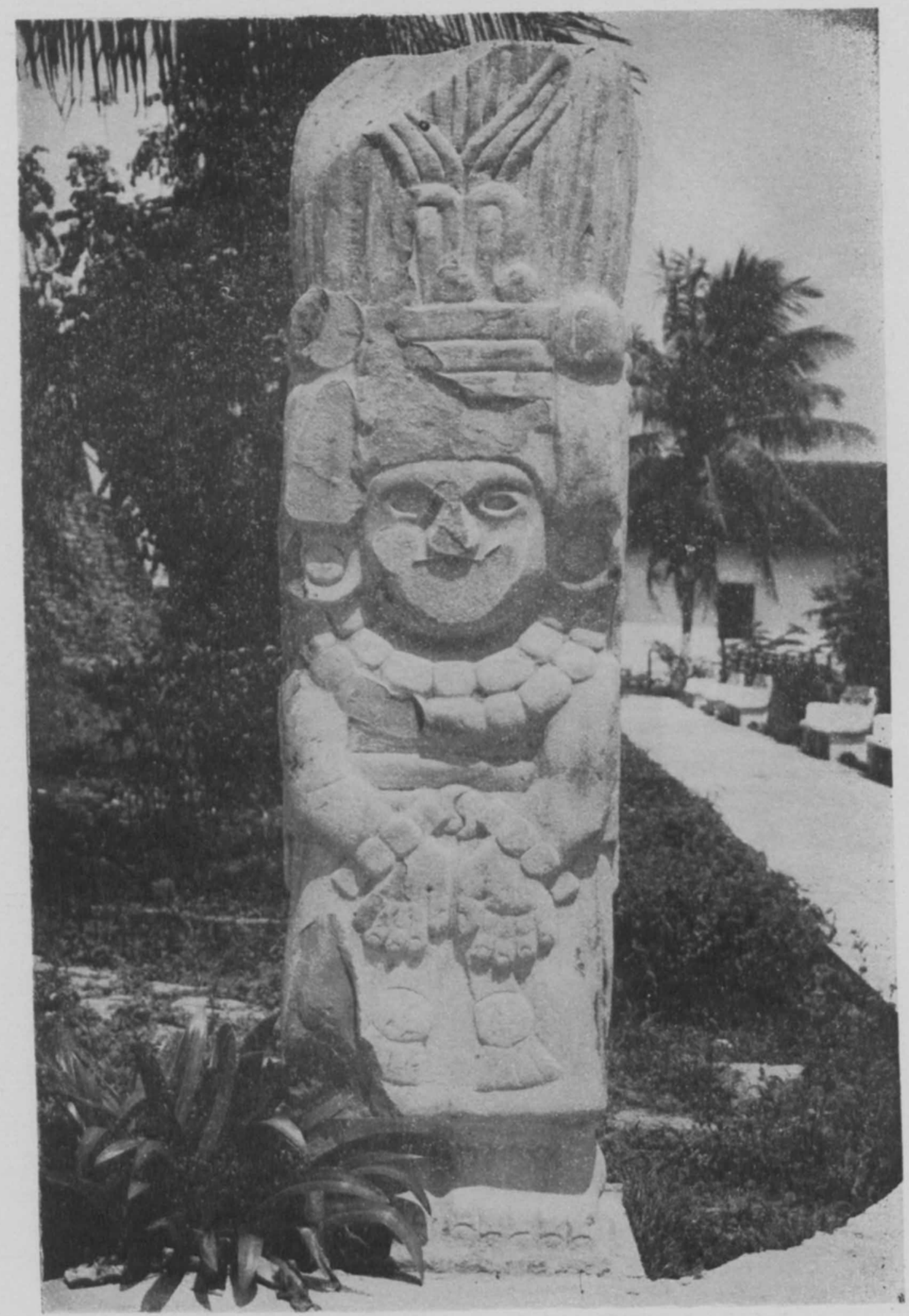

8. Ixcuimane (?). Escultura huaxteco-tolteca. 
DOI: http://dx.doi.org/10.22201/iie.18703062e.1958.27.647

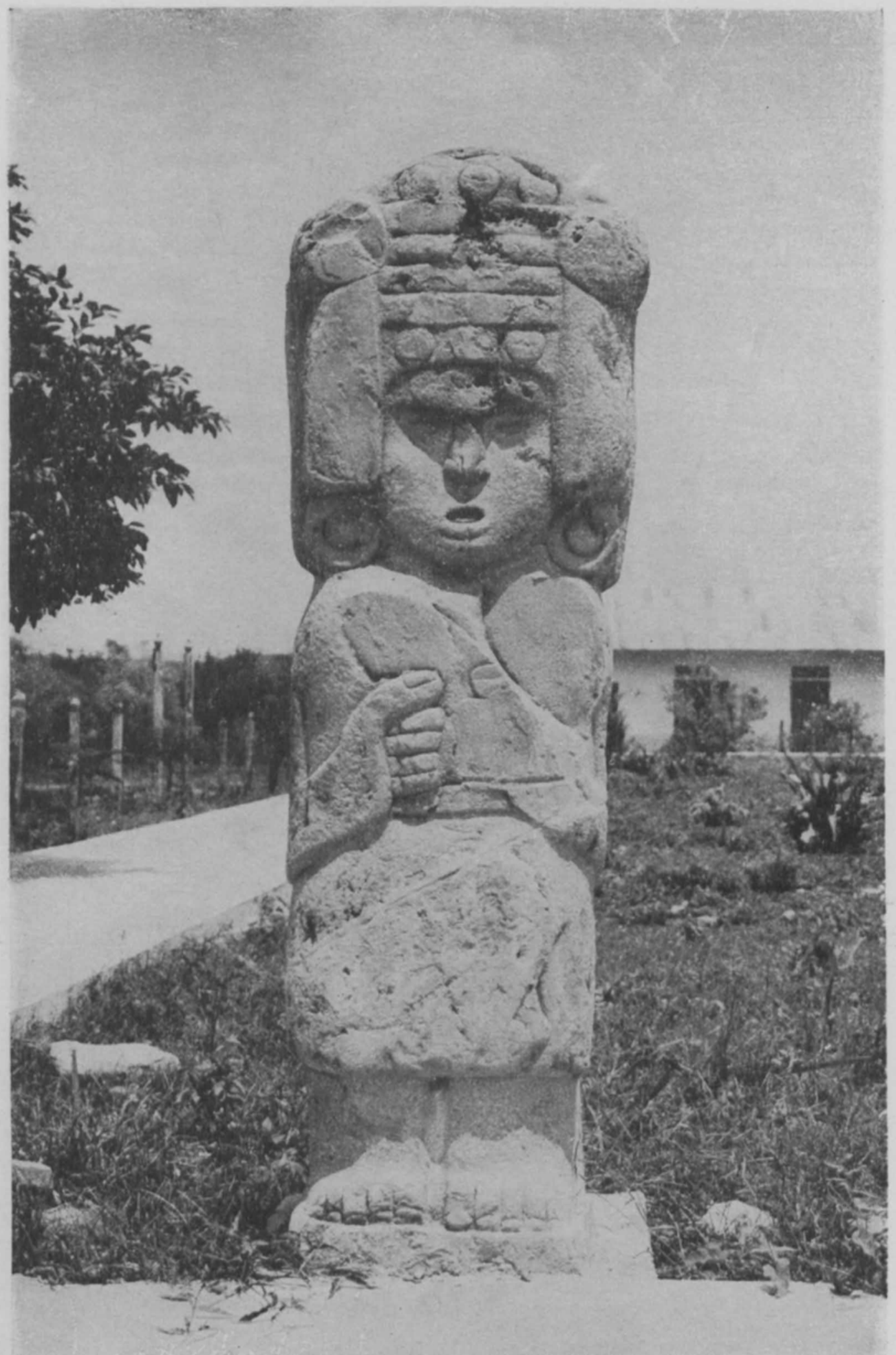

9. Escultura de sacerdote. 


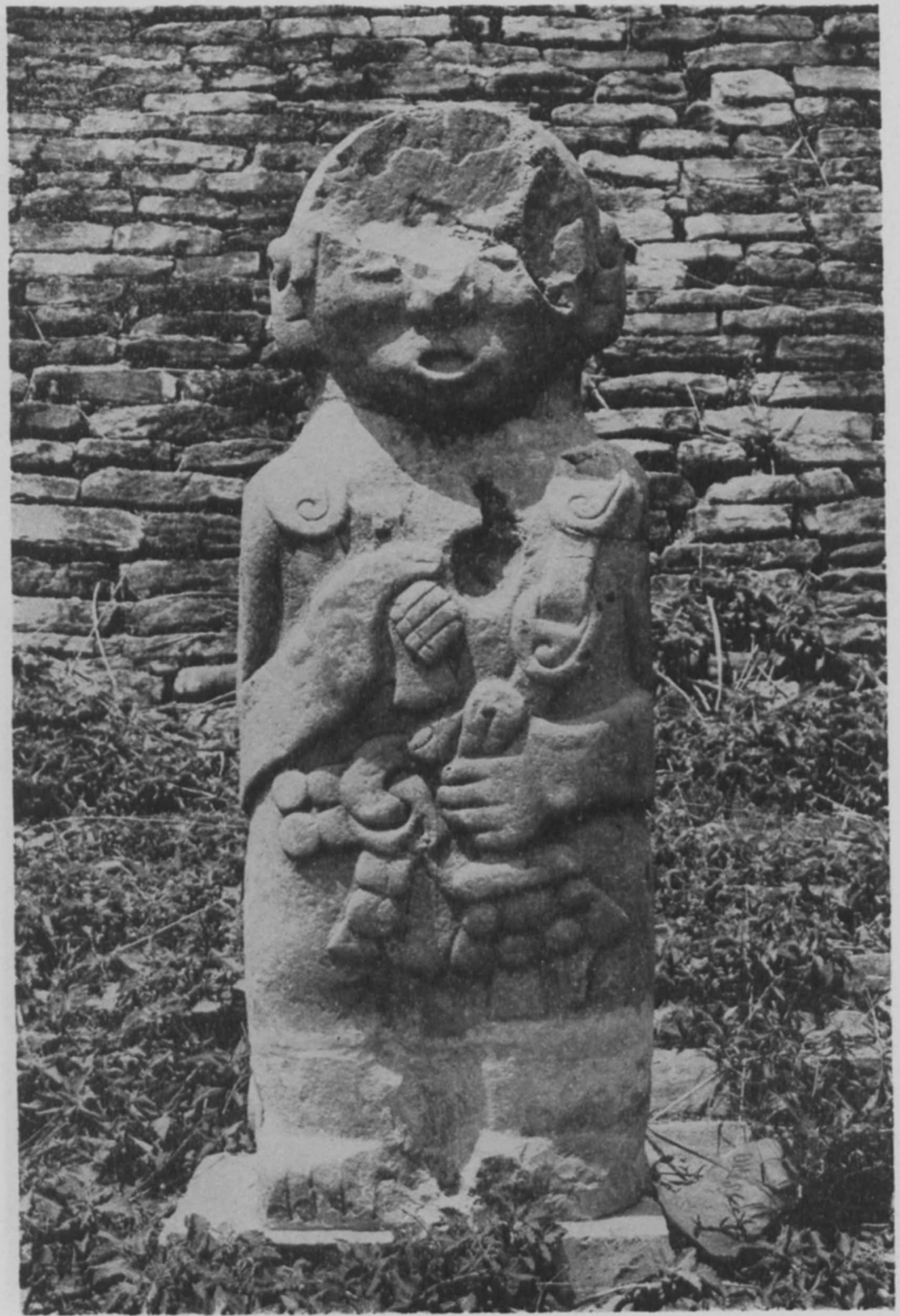

10. Xipe-Totec. 
DOI: http://dx.doi.org/10.22201/iie.18703062e.1958.27.647

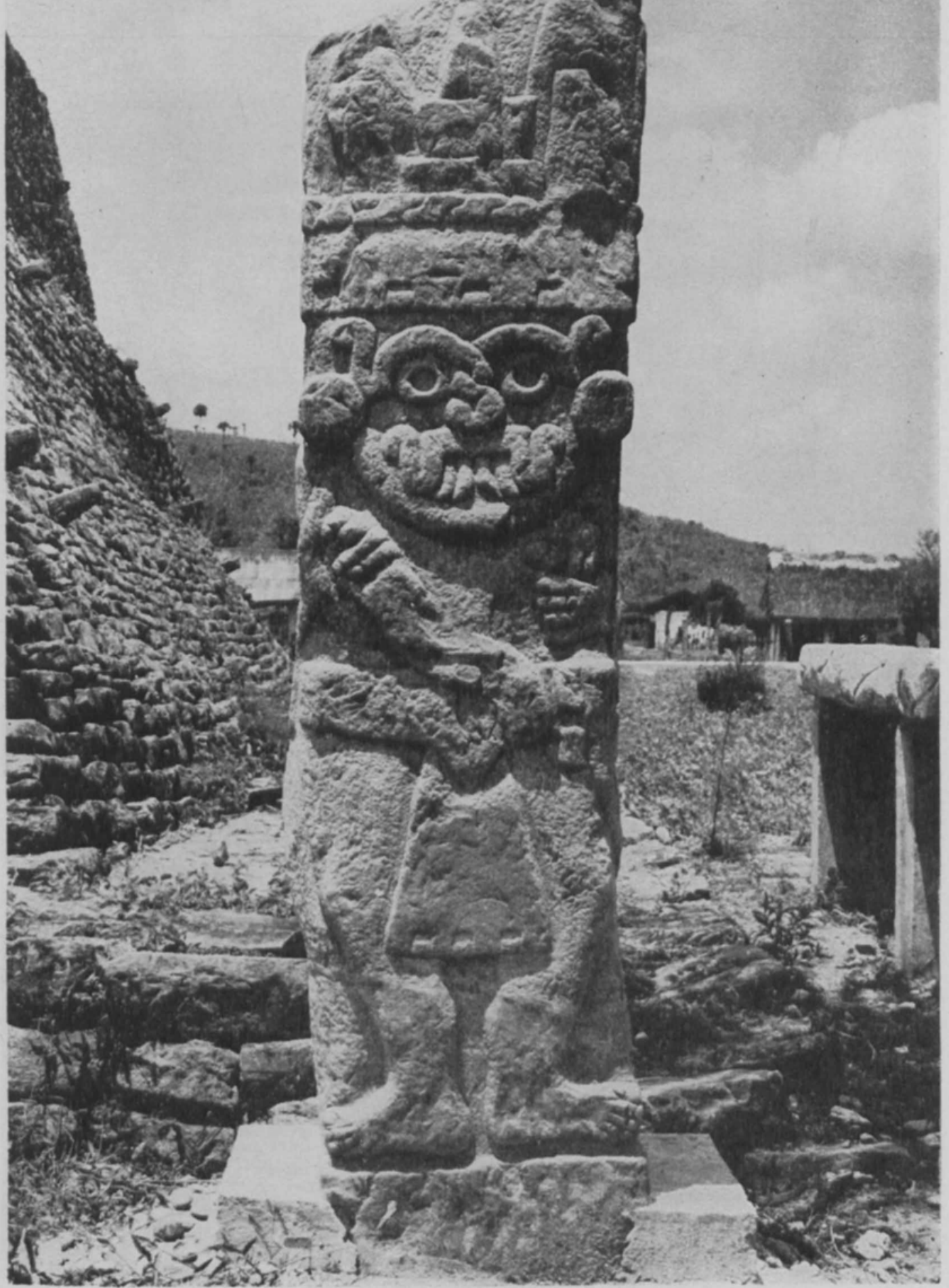

11. Escultura de Tláloc. 
DOI: http://dx.doi.org/10.22201/iie.18703062e.1958.27.647

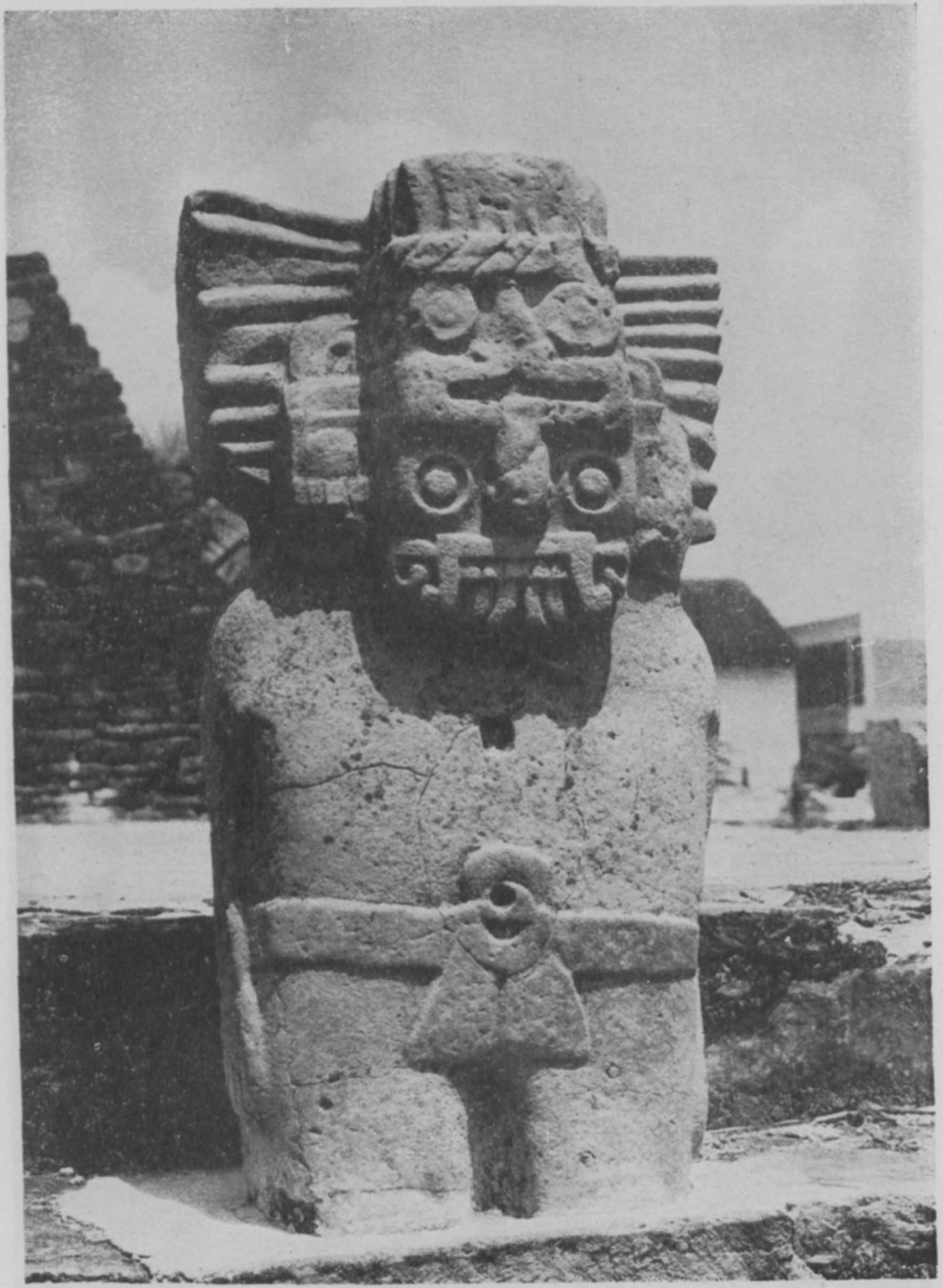

12. Escultura azteca de Tláloc. 
DOI: http://dx.doi.org/10.22201/iie.18703062e.1958.27.647

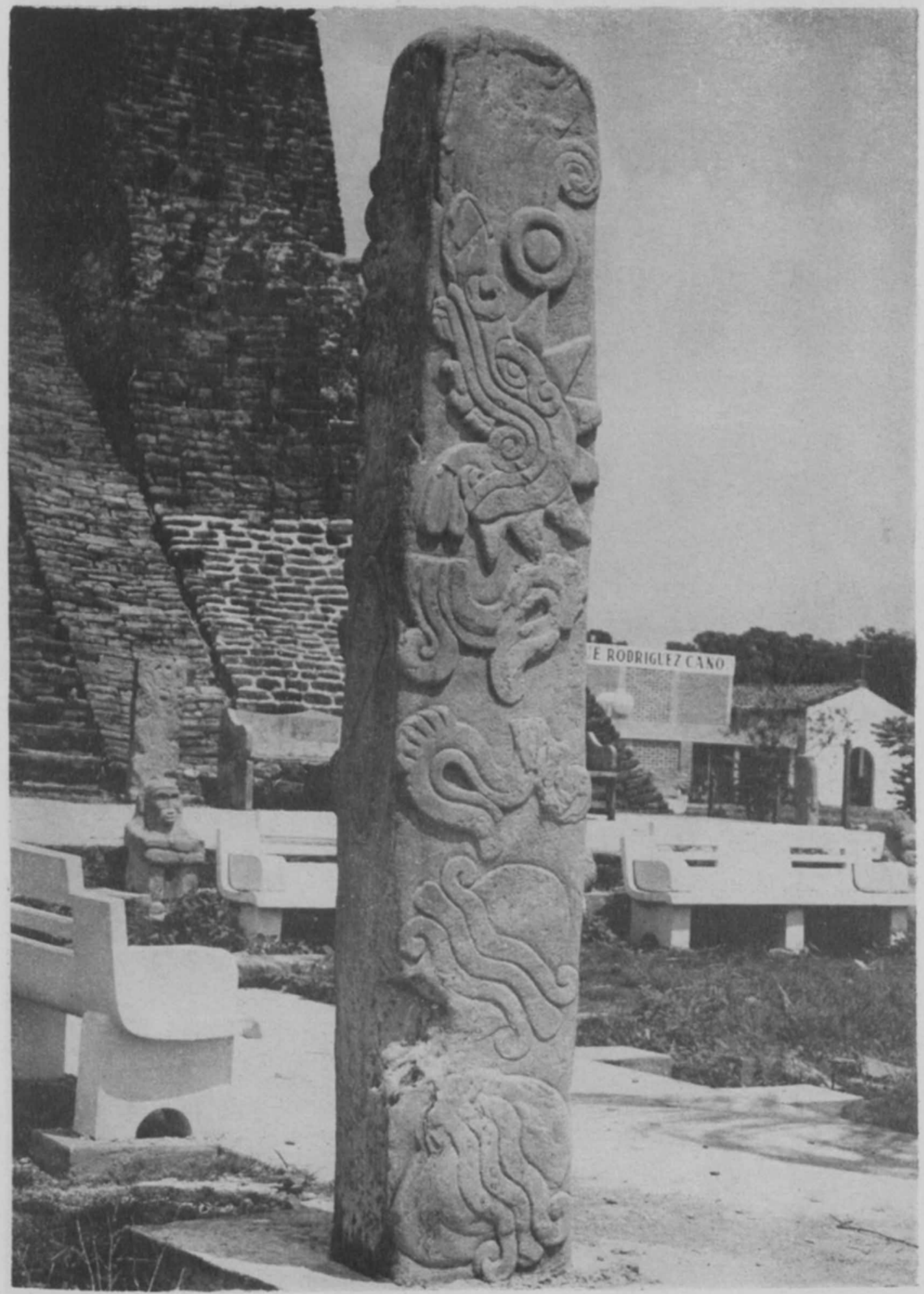

13. Calendario azteca. 
DOI: http://dx.doi.org/10.22201/iie.18703062e.1958.27.647

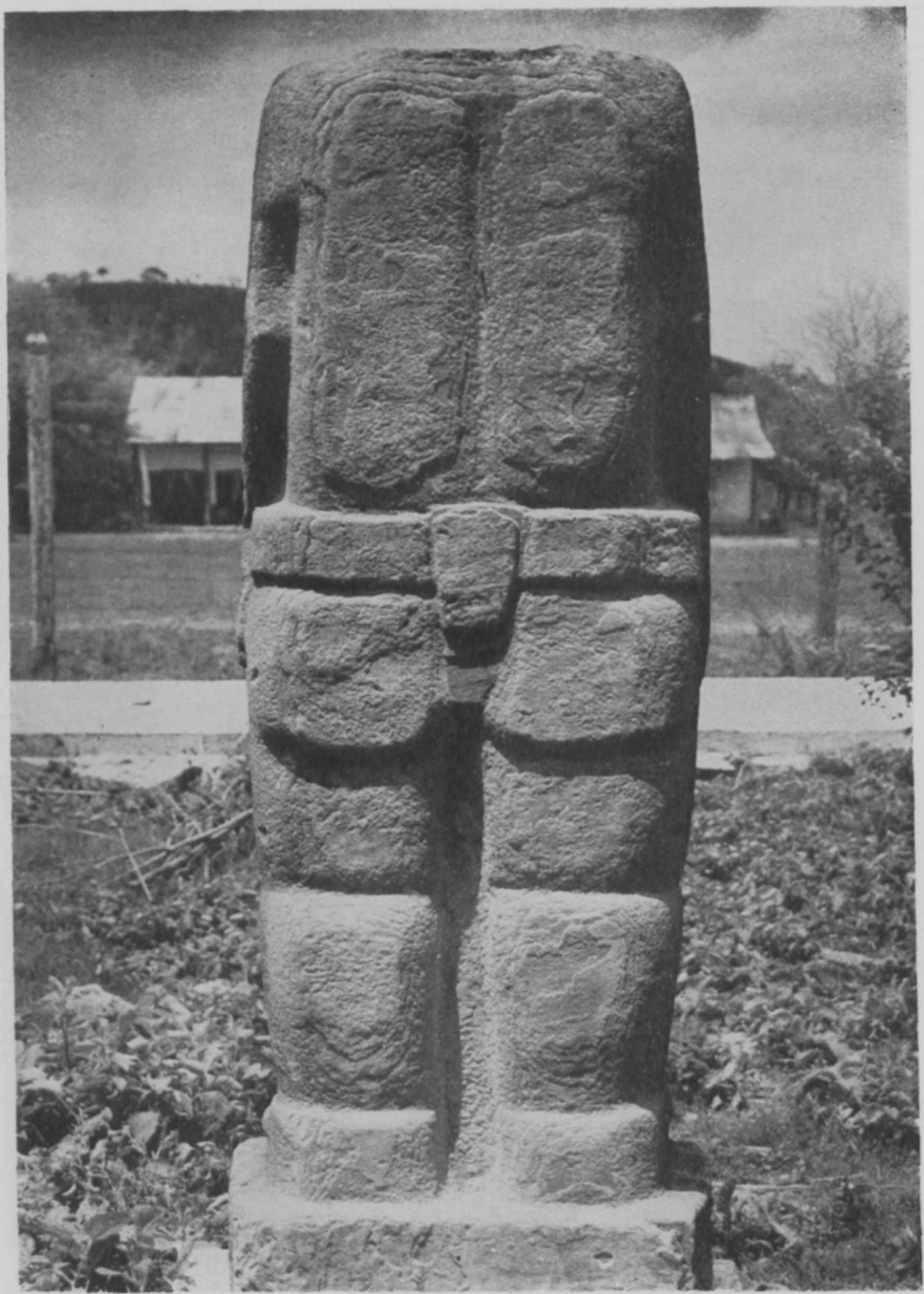

14. Escultura antropomorfa. 
DOI: http://dx.doi.org/10.22201/iie.18703062e.1958.27.647

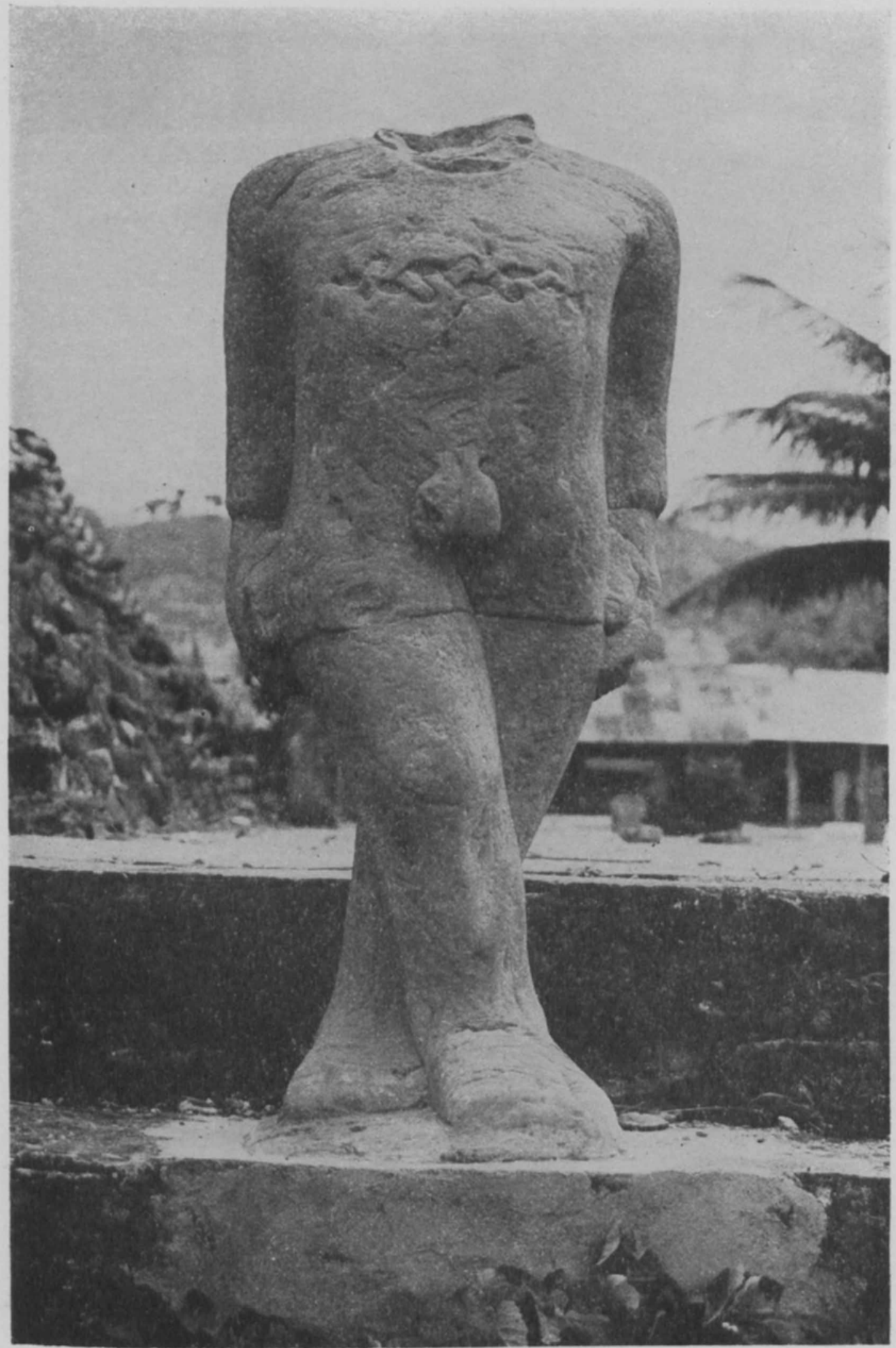

15. Escultura de Xipe-Totec. 
DOI: http://dx.doi.org/10.22201/iie.18703062e.1958.27.647

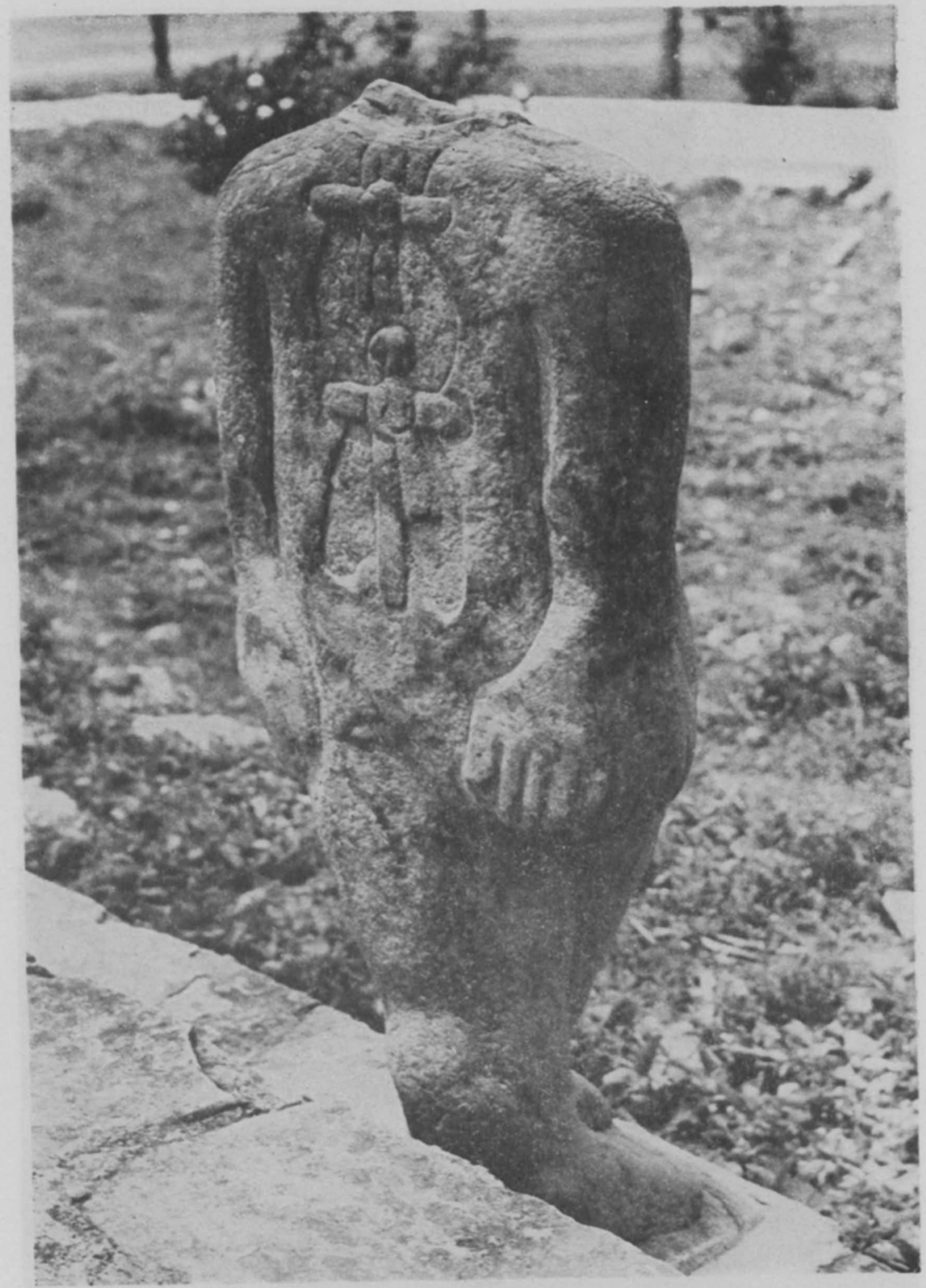

16. Escultura de Xipe-Totec. 


\section{La fase huasteca}

Hay sólo una pequeña escultura huasteca de significación artística en Teayo (lám. 5) ; corresponde a la deidad más comúnmente representada en la escultura de los pueblos de esta región, seguramente la más importante de su panteón: Ixcuiname o Tlazolteotl, diosa femenina de la fecundidad, del amor carnal y de la lujuria; patrona de los partos. La forma en que esta diosa huasteca -adoptada más tarde por los mexicas- aparece esculpida es siempre semejante: erguida, con los senos al descubierto y las manos sobre el vientre; el rostro muestra sus facciones serenas, casi inexpresivas y el tocado, inconfundible, está constituído por una venda de algodón sin hilar (originalmente, entre los huastecos fue la diosa del cultivo del algodón, entre otras funciones relacionadas con la fecundidad de la tierra) terminando hacia arriba con un gorro cónico aureolado por un resplandor semicircular.

Los escultores huastecos dieron siempre a esta diosa un tratamiento simplista y esquemático. En el caso de la figura de Teayo ese esquematismo fue llevado a un grado extremo: los brazos rigidos terminan en unas manos cuyos dedos apenas están sugeridos; los senos son dos diminutas semiesferas que emergen drásticamente sobre el plano del torso, y el rostro, aparentemente desproporcionado por su pequeño tamaño, se integra perfectamente a la composición de la figura siendo tan esencial que puede decirse que es el elemento que la "vitaliza", estableciendo un contraste entre su humanidad y la abstracta conformación del resto de la escultura (todo se reduce a círculos, esferas, conos y prismas). No es, desde luego, una de las más importantes representaciones de esta diosa huasteca, pero sí, formalmente, una de las de mayor interés plástico entre las que se han hallado.

\section{La fase tolteca}

Entre las esculturas huasteco-toltecas de Teayo destaca, en primer lugar, la de Chicomecoatl, "siete serpiente" (lám. 6), diosa de los mantenimientos en el antiguo México, "así de lo que se come como de lo que se bebe" según dice Sahagún. La representación escultórica de esta deidad es también inconfundible: una saya atada por una serpiente a manera de cinturón bajo los pechos desnudos, un tocado geométrico -amacalli- ornado por una mariposa en el centro y dos rosetones de papel en los ángulos superiores, además de un penacho culminante de plumas 
ricas. Chicomecoatl siempre fue reducida en escultura a una forma geométrica básica: el rectángulo; incluso entre los aztecas, sensuales y realistas en las formas de su arte. Más aún en un caso como este en que se trata de una obra huasteco-tolteca.

Evidentemente hay un nexo estilistico entre los "atlantes" gigantes de Tula y la Chicomecoatl de Teayo. La forma en que está concebido el cuerpo, sometido por completo al volumen del bloque escultórico con los brazos cayendo a los lados -en la obra de Teayo el amplio tocado los cubre - la hierática expresión del rostro e incluso el nudo del cinturón, son elementos que acentúan ese "aire tolteca de familia" si bien, estéticamente hablando, la Chicomecoatl aunque no tiene la monumentalidad de los atlantes demuestra mayor madurez en la intención de hacer con la forma una abstracción de la realidad, sin pretender ninguna relación sensual con ella, gracias al geometrismo heredado de los teotihuacanos; abstracto geometrismo que se acentúa en la parte posterior ocupada toda por el gran tocado compuesto a base de lineas verticales. Los artistas de Teayo encontraron la manera maestra de simbolizar -más que representar- el concepto de la diosa en la forma más escultórica posible puesto que por todos los ángulos que se mire no puede ser sino Chicomecoatl. El rostro es lo que menos importa para constituír el idolo por excelencia de la fecundidad; tan es asi que cuando por influencia del peculiar sensualismo de la cultura huasteca local se presentan, en la parte anterior, los ojos, la nariz, la boca y aun los senos con un ostentoso pezón, la feminidad de la diosa así establecida contrasta drásticamente con el tratamiento del atuendo ritual que la transforma en símbolo. Pero es precisamente de este encuentro de influencias plásticas - la geométrica y simbólica de los toltecas por una parte y la representativa y sensual de los huastecas por la otra- de donde surge el interés artístico de esta escultura.

Es probable que de este encuentro entre los pueblos nahuas y los del Golfo - toltecas y huastecos- ejemplificado en Teayo, haya partido la aceptación de Ixcuiname, deidad de los segundos, en el panteón de los primeros, en el que es conocida, principalmente, con el nombre de Tlazolteotl, pues no deja de ser significativa la presencia, en este mismo lugar, de un monolito que conservando de la principal diosa huasteca la característica actitud de las manos, abiertas sobre el vientre, está esculpido en un estilo definidamente tolteca (lám. 8).

Tanto esta última escultura como la de otra deidad femenina de đifícil identificación (lám. 9) y la de Xipe Totec (lám. 10) responden 
a un concepto formal que difiere del de las otras piezas que hasta ahora han sido aqui tratadas. Es de suponerse que existiendo en Teayo un pueblo autóctono huasteco, creador de obras como la Ixcuiname de la lámina 5, éste fue influenciado profundamente por la cultura tolteca, como lo demuestra la escultura de Chicomecoatl (lám. 6), originándose así un núcleo humano de huastecos toltequizados en cuyo seno se realizó una síntesis estilistica de la que surgieron obras como estas tres últimas (láminas 8,9 y 10); esculturas hechas con un sentido plástico más representativo que simbólico en concepto formal, más sensual que abstracto en tratamiento; en realidad todo un "estilo" original y propio de Teayo, gustoso de lo redondeado, de lo táctil en el sentido más lato de la palabra, para lo cual se prestaba perfectamente el material escultórico de la región, una roca blanda de origen sedimentario.

Estas tres últimas esculturas parecen ser representación no ya de dioses sino de sacerdotes ataviados para la ceremonia. En las tres se recurrió a trastocar la posición de los dedos de la mano derecha con el objeto de mostrarlos hacia el frente con una intención de carácter evidentemente mágico, quizás en relación con el sacrificio humano ya que entre los dedos llevan un cuchillo de pedernal. En este estilo escultórico -el "estilo de Teayo"- la figura de Xipe Totec es una obra de primer orden. Desgraciadamente la deleznable calidad del material ha sido factor decisivo en su destrucción y la reconstrucción absurda que manos ineptas hicieron de sus piernas han dado al traste con sus proporciones originales.

\section{La fase azteca}

A mediados del siglo xv, durante el reinado de Moctezuma Ilhuicamina, los mexicanos invadieron la huasteca llegando hasta la región del Pánuco, estableciéndose así un intercambio comercial, religioso y cultural entre el pueblo invasor y los pueblos invadidos. Algunas ciudades importantes de la costa conservaron sus características regionales no obstante la pujanza de la cultura mexica, pero otras, más débiles - recuérdese Cempoala - fueron absorbidas completamente por esta última. Teayo, que desde luego no era ya muy importante dentro de la órbita huasteca puesto que había sido nahuatlizado por los toltecas, se identificó con la vida y el arte aztecas en forma absoluta convirtiéndose en un centro religioso de cierta magnitud, como lo prueba la pirámide que alli se erigió, posiblemente sobre algún monumento anterior de menor importancia. 
La escultura que a partir de ese momento se ejecutó en Teayo responde al carácter, al espíritu y a la forma de la escultura azteca. Apenas alguna que otra obra recordará lejanamente las actitudes de las esculturas de la fase anterior. Tal es el caso del Tlaloc que aparece reproducido en la lámina $11 \mathrm{y}$ al cual Seler no conoció puesto que fue descubierto, poco tiempo después de que él visitó la región, por Teobert Maler. Se trata de la figura de un sacerdote del dios del agua que lleva sobre el rostro una impresionante máscara con las caracteristicas serpientes enlazadas rodeando los ojos y formando la nariz, además de otra serpiente que al constituir la boca deja asomar los colmillos. A semejanza de las esculturas toltecas de la época anterior lleva en la mano derecha el cuchillo de sacrificios mostrando los dedos hacia el frente y en la izquierda una bolsa de copal. En el tocado aparece el signo mixteco del año: un ángulo enlazado con un trapecio (semejante a los glifos del año del Códice Borgia) que hace pensar en un curioso traslado del registro calendárico del sur de México a la costa del Golfo por intermedio de los mexicanos, lo que concuerda con una de las hipótesis de Alfonso Caso quien supone que "los mixtecos adoptaron el calendario tolteca a fines del siglo $\mathrm{x}$ y a partir de entonces los glifos mixtecos están estrechamente emparentados con los mexicanos". 5 Desgraciadamente los relieves que acompañan al glifo, por su estado de destrucción, impiden detallar alguna fecha significativa.

Pero si ese Tlaloc conserva aún ciertos elementos estilísticos toltecas, el Tlaloc que aparece reproducido en la lámina 12 es ya diferencialmente azteca por su característica y extrema síntesis formal que acentúa la abstracción religiosa que representa. El cuerpo, de hecho, carece de importancia: el maxtlatl que cubre el sexo de la deidad y los brazos que caen a los lados están apenas sugeridos. En contraste, la cabeza es de una intensidad expresiva admirable, puesto que es la que define a Tlaloc y por ende la parte más importante de la obra. No sólo la máscara muestra los inconfundibles atributos faciales del dios sino que aun el tocado, adornado en su parte posterior por un gran moño de papel plegado, repite la imagen con una insistencia mágica. En esa cabeza extraordinaria está concretado lo metafísico, petrificado el concepto de Tlaloc con todas sus implicaciones mitológicas.

5 Caso, Alfonso. El Calendario Mixteco. En la "Revista de Historia Mexicana", núm. 20. El Colegio de México, abril-junio de 1956. 
Hay en Teayo un monolito que es de un gran interés por ser una de las poquísimas estelas calendáricas aztecas que se conocen (lámina núm. 13). En su cara principal y en la parte más alta ostenta la fecha ce cipactli (uno lagarto) coronada por un penacho de plumas. En la parte inferior aparecen dos partes seccionadas de una serpiente, ejecutadas con tal sentido de la dinámica escultórica que parecen aún palpitar en la piedra en los estertores del mito de Xiuhcoatl, la serpiente de fuego, y más abajo todavía están dos corazones divididos en su parte central por las ondas de sangre del sacrificio. La estrellada aureola del cipactli se continúa en otra de las caras, en la cual aparece, finamente ejecutada, la fecha trece caña. En las dos caras restantes están los relieves de los glifos calendáricos trece flor y uno pedernal respectivamente, el primero de ellos trabajado con una delicadeza excepcional.

Según Seler "se debe combinar el día uno lagarto con el año trece caña y el día trece flor con el año uno pedernal puesto que la primera de estas dos fechas dobles indica el principio de un tonalamatl* y la segunda marca exactamente el día final del mismo". ${ }^{\circ}$

Entre las esculturas aztecas de Teayo existe un ejemplar que o bien no fue terminado por completo o la erosión sufrida por la piedra en que está realizado lo ha dejado en el estado en que actualmente -y desgraciadamente- se encuentra (lámina 14). Representa a un hombre de pie y en posición frontal, sólo que por su parte anterior ha perdido todo su relieve. Por detrás, sin embargo, puede observarse un formidable tratamiento escultórico estrictamente azteca por la magistral captación de los rasgos esenciales de la figura humana. No es necesaria una línea más en el suave relieve para definir un cuerpo, pero si se eliminara una sola de las que tiene dejaria de ser ese cuerpo tan pleno de sugerencias vitales. Nada hay allí de naturalismo, muy al contrario, se ha llegado a la más increible síntesis por el camino de la eliminación de todo lo que es superfluo para definir la esencia formal del hombre; y todo eso gracias a una sublimada intelectualización geometrizante que tiene como base -nuevamente resurge el trascendentalismo estético de Teotihuacánel rectángulo.

Pero en ese insólito jardín de Teayo, como en todo museo, hay una obra maestra incomparable. Es ésta una figura de Xipe Totec a la cual le falta la cabeza. El sacerdote del dios, de pie y en un tamaño casi

* Ciclo calendárico ritual de 260 días.

6 Seler, Eduard. Op. cit. 
natural, aparece en una extraña actitud de danza, con una pierna cruzada sobre la otra y el torso cubierto por la piel del sacrificado según la costumbre ceremonial en el culto a este dios - "nuestro señor el desollado", dios de la primavera.

Esta, como otras representaciones de Xipe que se conocen, constituye la máxima prueba de la extraordinaria calidad estética de la escul-

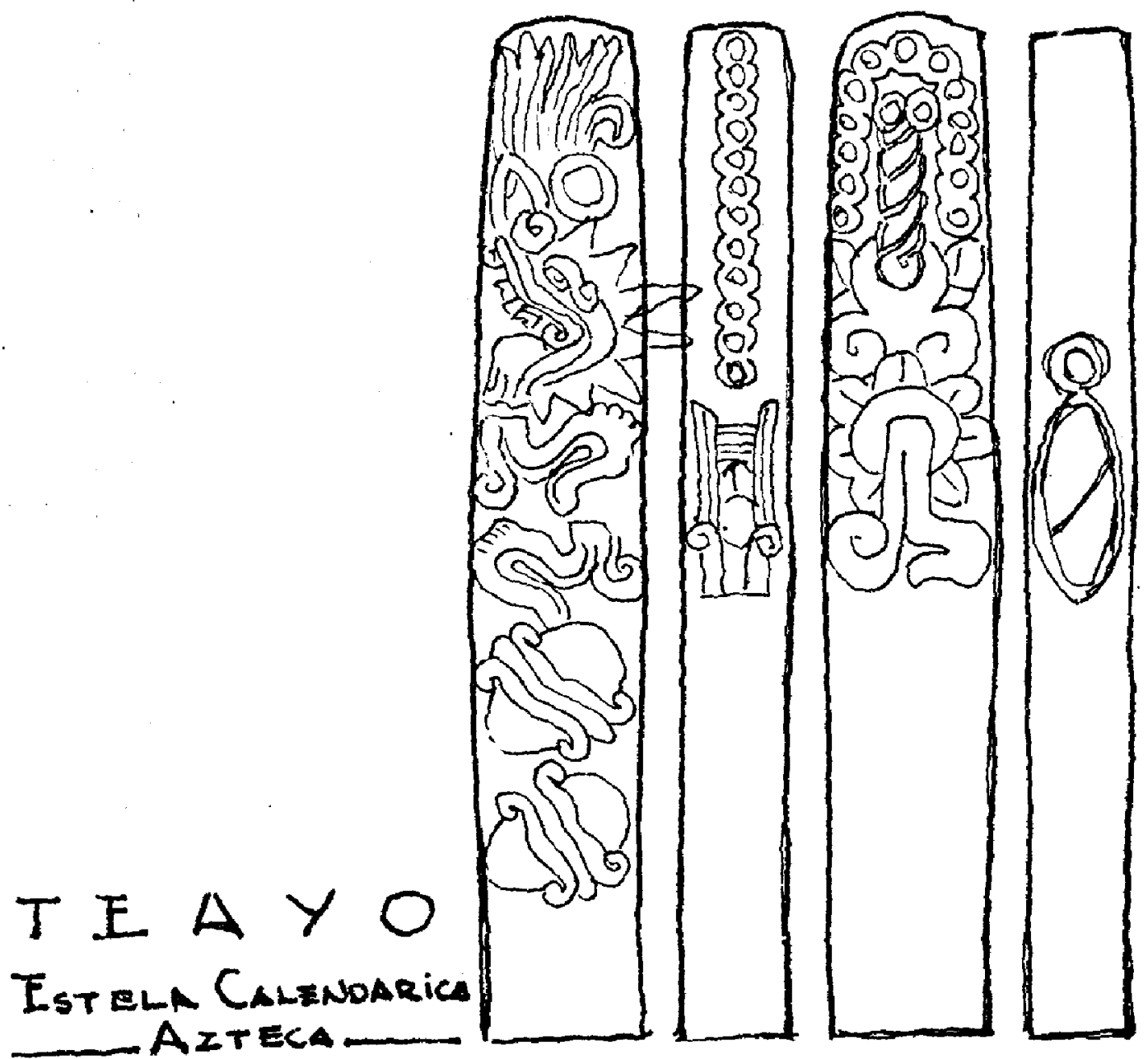

Estela calendárica. Relieves de sus cuatro caras. Dibujo de R. F. G., según el levantamiento de Seler.

tura azteca, capaz de sublimar inclusive un rito como este que es, indudablemente, el que más puede repugnar a la mentalidad occidental por su refinada crueldad, rito que para los mexicanos no era otra cosa que la referencia mágica al cambio anual de la piel muerta de la tierra por una nueva capa verdeante de vegetación. 
Frente a obras de arte como ésta el hecho concreto pierde sentido. Lo que importa es la magistral capacidad de los escultores indigenas por crear, a partir de una realidad histórica, vivida en un momento dado, otra realidad superior a toda anécdota, perdurable en el tiempo y por encima de toda creencia mágica o religiosa, la realidad, inasible aun para las cambiantes doctrinas estéticas, del gran arte. Trascendental realismo el de esta escultura que en su danza serena aparece cubierta con la piel del sacrificado recosida en la gran herida del pecho, los testículos vacíos al aire y las manos fláccidas colgando tras las manos reales del sacerdote.

Existían en Teayo cuando menos otras dos esculturas de Xipe -que Seler publicó en su estudio- cuyo paradero no me ha sido posible conocer. Sin embargo ninguno alcanza la perfección de esta última.

Es curioso observar que en Teayo, desde la época huasteca más antigua hasta la azteca, las esculturas están íntimamente ligadas con la fertilidad de la tierra: Ixcuiname, Chicomecoatl, Tlaloc, Xipe Totec. Evidentemente Teayo siempre fue un centro religioso en el que se propiciaba a los dioses relacionados con la agricultura y la vegetación. No era pues un centro guerrero sino un santuario necesario para la protección religiosa de los cultivos en esa rica región costera. Hasta la estela calendárica así parece indicarlo.

No obstante la prestancia curiosa y agradable de las esculturas en medio de la vegetación del jardín de Castillo de Teayo, la erosión causada por la intemperie sobre las piedras en que están hechas, impone la construcción de un museo local que puede irse enriqueciendo con las nuevas piezas que se hallen en los alrededores.

En este estudio no han sido tratadas todas las esculturas de este original museo al aire libre, pero sí todas aquellas que considero de interés para los estudios estéticos, arqueológicos e históricos de una de las regiones más complejas y poco conocidas de Mesoamérica. 